disease cases with seasonal plagues of flies. Professor Greenberg deals with these examples in an open-minded way, admitting where the evidence is slight and emphasising where new research efforts should be directed.

The book has an extensive bibliography, including many early works. The style of the illustrations is very variable and occasionally disappointing, but the volume as a whole will be a useful source of information and reference for public health workers, epidemiologists and entomologists alike.

David Rogers

\section{Image of a scientist}

Science as a Career Choice: Theoretical and Empirical Studies. Edited by Bernice T. Eiduson and Linda Beckman. Pp. $x v+735$. (Russell Sage Foundation: New York, 1973.) £10.40.

WHY I feel able to embark upon the formidable task of reviewing this work, which is a vast book largely concerned with psychological theory and studies of the process of socialisation, is that the choice of career is a crucial factor in economic analysis of the way in which the labour market works. It is therefore necessary to review as much of the evidence as possible presented by a variety of disciplines in order to see what it is that drives people to make one choice rather than another.

This interesting study is a collection of papers concerned with the mechanisms of career choice and the way that people drift into the physical and other sciences, and what sort of people they are. Scientists apparently (page 670)

"lead quite, unpretentious, eventenored, rather steady lives. They come home regularly for dinner, and spend the time before and after dinner with their children and wives; pursue their hobbies systematically; and more often than not, spend the evenings reading journals, novels, magazines, or watching television. Most live on a fairly modest scale and do not spend much for theatres or entertainment... despite the fact that their home lives are interesting and varied, one gets the impression that these do not reflect their most exciting selves. For one thing, the interviews reveal that the scientists are not able to give the most significant parts of themselves to home and family."

To an outsider, this is an extraordinarily perceptive description of the home lives of many scientists, and also suggests the degree of secretiveness and obsession with work which has seemed so often a characteristic of scientists with whom one has been thrown into contact. Terman seems to have shown that scientists chose a subject early, and that their early socialisation tended to isolate them by making them feel different from other children. According to other studies, those people who are going to take up science develop an image of a scientist which tends to become selfconfirming: the scientist is committed, studious, collaborative, concerned primarily with science; and that this perpetuation of a self-image which is assisted by highly developed social structures therefore tends to make the scientific community a fairly close one which is self-recruiting. This would also suggest that it was a social system which tended to push other people out, particularly people who developed an interest in science later in life, or people who had unusual social characteristics.

This description of the physical scientists contrasts markedly with those who call themselves social scientists. There seems to be some evidence that physical scientists come from individualistic and rather cold families (page 17) with high intellectual motivation. There is also, it seems, some evidence that the classic image of the pure scientific researcher clashes somewhat severely with most scientists' actual experience of their work. Interestingly enough, there are astonishingly few female or black scientists in the American studies which are cited here, and therefore the scientific community in the United States may be described as predominantly white and male, thus presumably reinforcing the tendencies towards a self-perpetuating community which have just been outlined.

The editors point out that the evidence, although very bulky, is in fact sketchy and derived from a great many partial studies of certain aspects of the problem, and therefore the very brief allusion which has been given here to some aspects of the work must be treated with great caution. Nevertheles, it does illustrate the probability that career choices between becoming a non-scientist or a scientist, and within the sciences, are largely affected by what economists would regard as irrational motivations, and also implies to the outsider that there must be a considerable number of peoplc inside science who have been attracted into it by their own fantasies and who are now living in a world in which their fantasies clash rather sharply with reality. This may not be an untypical situation, but presumably it must be particularly disillusioning inside a closed profession like science, where so much of the original choice of career has denended upon high hopes and aspirations.

JOHN VAIZEY

\section{Lymphocyte dogma}

$T$ and $B$ Lymphocytes. By M. F. Greaves, J. J. T. Owen and M. C. Raff. Pp. vii +316 . (Excerpta Medica : Amsterdam; American Elsevier: New York, 1973.) £14.08.

Hert is a book to fill with joy the hearts of cellular immunologists. So many pages devoted to $\mathrm{T}$ and $\mathrm{B}$ lymphocytes and only $4 p$ per page.

I' and B lymphocytes, by which is meant lymphocytes derived from the thymus and lymphocytes derived from the bursal equivalent (whatever that is) respectively, have after a shaky start in the $1960 \mathrm{~s}$ become all the rage at the beginning of the 1970s. The present book represents a sort of consummation of this rage.

The history of the notion of two modalities of lymphocytes is given pari passu with a general account of the relationship between the immune response and the lymphoid system. The variously described properties of $\mathrm{T}$ and $\mathrm{B}$ lymphocytes are adequately documented. The authors go in detail into the mysteries of $\mathrm{T}$ and $\mathrm{B}$ lymphocyte participation in immunological responses and as a rousing finale consider the clinical applications of $\mathrm{T}$ and $\mathrm{B}$ lymphocyte theory. There is an appendix said to deal with the manipulation of $\mathrm{T}$ and $\mathrm{B}$ cell responses and an extensive and up-to-date reference list. The index could be more comprehensive but the diagrams and illustrations are good.

It seems on compelling evidence that the various chapters of the book have heen written each by a different author but the blend overall is eminently readable and not markedly reiterative. Further, there are many and healthy instances in which ignorance in relation to particular points of fact is stressed. The book is heavily orientated towards work on mice but in this respect it reflects the activities of the bulk of contemporary cellular immunologists.

Greaves, Owen and Raff are to be congratulated on a timely and carefully prepared book which, despite its vrice, will be a boon to teachers of immunology. The only danger in it is that it will be seen as an orthodox statement of fact rather than what it is, the enunciation of a most interesting working hypothesis.

\section{A. J. S. Davies}

\section{Erratum}

IN the illustration "Butterfly Collection" $(248,289 ; 1974)$ the habitats of Idea hypermnestra and Marpesia chiron should have been given as Malaysia and South America respectively. 